\title{
MAIS UM HIMENOMICETO DESTRUIDOR DA MADEIRA
}

\author{
A. Ribeiro Teixeira
}

\section{INTRODUÇÃO}

Ao fazermos o estudo das Thelephoraceae responsáveis por podridão da madeira (7), focalizamos apenas uma espécie do gênero Hymenochacte, $I I$. berkeleyana (Mont.) Cooke, visto não possuirmos, no momento, bom material de outras. Chegando-nos, agora, um bonito espécime, resolvemos publicar esta nota, para assim aumentar o número das espécies brasileiras estudadas.

Queremos frizar que, à medida que formos encontrando himenomicetos ainda não descritos dentro do plano de estudos por nós traçado (6), os iremos descrevendo e publicando, na medida do possivel, para que aquelas pesquisas sejam satisfatoriamente rompletadas.

Os nomes das côres, dados entre parêntesce, foran tirados do dicionário de Maerz e Paul (2).

\section{Hymenochate sallei Berli. o Curtis \\ Liun. Soc. Bot. Journ. 10: 333. 1868. (1)}

Sinonimia Strem elegantissimum Speg., Soc. Gient. Argentina Anal. 16 : 38. 1883. - S. lonuis:imm Fries, R. Soe. Sci. İpsal, Antis III. 1: 111. 1851. - Hymenochaete tenuissima Berk., Linn. Soc. Bot. Joum. 10 : 333. 1868. (1)

Hymenochact tefanlissimo (Speg.) Saceardo, Sylloge fungorum 6: 594 . 1888 . (4)

Distribuição geográfica : Foi assinatada na Carolina do sul e Flórida (JE. UU.), México. Am. Contral e do Sul $(1,2)$. Sabemos do sia presença no Brasil, segundo Burt (1). e por observação própria em matcrial coletado por P. R. Azevedo, no pátio de dormentes do I. P. T., Butantã, são Paulo, Est. S. Panlo. em 3 de Abril de 1946, e arquivado no Herb. Mir. Seeção de Botânica, I. A.. Campinas, Est. S. Paulo, sol n. $10^{\circ} \mathbf{5 3 6 2}$.

Essêneia atacada : O espécime em nossas mãos foi roletado sôbre um dormente da F. F. Sorocabana, de sapucaia branca (Lecythis sp.). 


\section{Diagnose :}

PÍLEO : (fig. 1, 2) sésil, muito imbric ado ; muito delgado, coriáceopapiráceo, flexírcl ; quando isolado (fig. 2), conchiforme, 7-10 x 8-12 mm; quando confluente (fig. 1), forma um conjunto de até $4 \mathrm{~cm}$ extenso. Superfície: pubescente, com pêlos adnatos ; castanho-fẻrrugínea (Russian calf) a castanho-amarelada (Cinnamon Brown), radialmente sulcada, raras vêzes apresentando-se zonada em zonas castanho-vinosas, brilhantes. Margem: muito ondulada, com bordos amarelados, semi-lobados.

CON'IEXTO : (fig. 3) 350-500 $\mu$ espêsso, de mesma côr que a superfície ; homogêneo, não possui camada escura, densa, de hifas, junto da superfície. Hifas do contexto : (fïg. 4) castanho-amareladas, não reagem em $\mathrm{KOH}$; de paredes finas o largo lúmen, muito septadas, ramificadas ; arranjadas radialmente no píleo ; variam de $3-4,5 \mu$ de diâmetro.

HIM FNIO : (fig. 5) de mesma côr que a superfície, tornando-se amarelada para a margem ; uniforme, não fendilhado ; com o auxílio de uma lupa, podem ser vistas as setas negras, eriçadas. Setas: (fig. 6) em camada única, partindo do sub-himênio ; denegridas, longo-acuminadas, resistentes, uniformemente espalhadas ; $65-110 \mu$ longas, $10-12 \mu$ de diâmetro, emergindo 40-60 . Basídias: (fig. 7 ) hialinas, clavuladas, $12 \times 4 \mu$. Esporos: (fig. 8) semi-hialinos, muito ligeiramente citrinos, lisos, cilindrico-elipsóides, $1,5-1,8 \times 3,5-4 \mu$.

Observacoões: Fotografias de píleos podem ser vistas em Burt (1) e em Rick (4) (como H. tenuissima Berk., Est. II, fig. 4). Ilustração da parte anatômica, esquemática apenas, encontramos em Burt (1).

Esta espécie faz parto de um grupo de quatro, cujos componentes são pileados, efuso-reflexos ou sésscis, não estratosos, i. é, com apenas uma camada de setas, com o contexto desprovido de uma camada escura de hifas separando-o da superfície. Essas quatro espécies são:H. aspera Berk. e Curtis, $H$. borealis Burt, $H$. berkeleyana (Mont.) Cooke, e $H$. sallei Berk. e Curtis, das quais descreremos, já, apenas as duas últimas.

\section{LITERATL:RA CITADA}

1. Burt, E. A. The Thelephoraceane of North America. X. Ann. Mo. Bot. Gard. 5 : 301-370. fig. 1-32. est. 16-17. 1918.

2. Maerz, A. e M. Rea Paul. Em A Dictionary of Color. pp. 1-207. pl. 1-56. 1. ed. McGraw-Hill Book Company, Inc. New York. 1930.

3. Overholts, L. O. Agaricales. $E m$ Seaver, F. J. and C. E. Chardon. Scientific Survey of Porto Rico and The Virgin Islands. New York Acad. of Sici. 8 : 148-176. 1926. - à pg. 151 .

4. Rick, J. Pilze aus Rio Grande do Sul (Brazilien). Broteria 5 : 5-j3. est. 1-6. 1906.

5. Saccardo, P. A. $\mathrm{Em}$ Sylloge fungorum $6: 1-928.1888$.

6. Teixeira, A. R. Himenomicetos brasileiros - Auriculariales e Dacryomycetales. Bragantia 5 : 153-186. cst. 1-14. I. A., Campinas, 1945.

7. Teixeira, A. R. Himenomicetos brasileiros Hymeniales, Thelephoracae. Bragantia 5 : 397-434. est. 1-16. I. A., Campinas, 1945. 

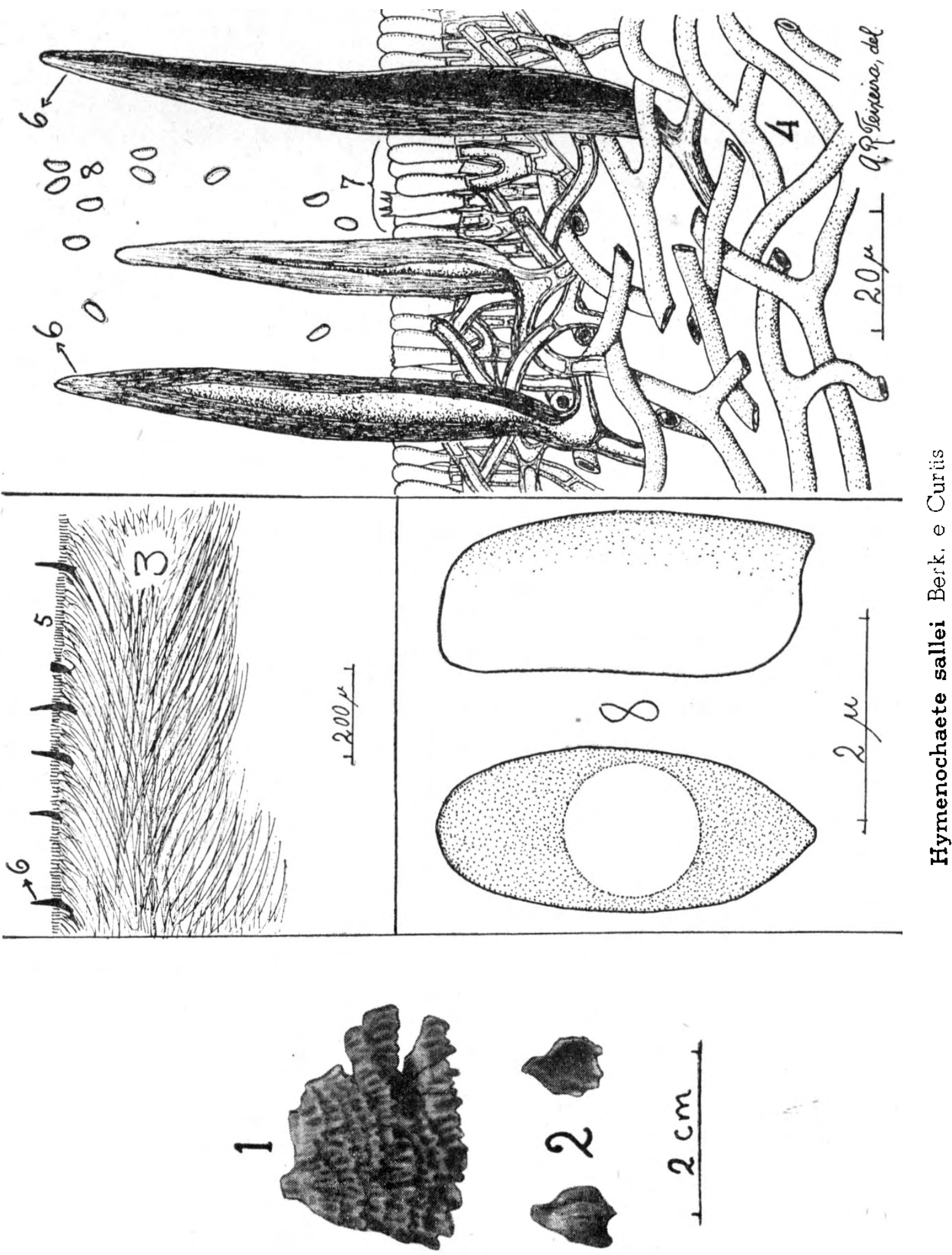